\title{
APLICAÇÃO DE MEDIDAS ANTIDUMPING PELOS ESTADOS UNIDOS NA IMPORTAÇÃO DE SUCO DE LARANJA BRASILEIRO
}

Helena Arriola Sperandio

\section{RESUMO}

As medidas de defesa comercial são impostas com a finalidade de proteger a indústria nacional de práticas desleais do comércio, como é o caso do dumping. Houve uma significativa importação de suco de laranja brasileiro por parte dos Estados Unidos, o que ensejou a aplicação de medidas antidumping para proteção da indústria doméstica norte-americana. As medidas foram impostas através de decisão do Departamento do Comércio dos Estados Unidos, no entanto, gerou preocupações, levando o Brasil ao Órgão de Solução de Controvérsias da OMC para dirimir tais questões.

\section{ABSTRACT}

Against the illegal commerce practices, the defense measures regarding commerce are imposed in order to protect the national industry against the illegal practices of commerce, such as dumping. There was a significant increase in the orange juice importation by United States of America, which made necessary the implication of anti-dumping measures to protect the North American domestic industry. The measurements were imposed by the decision of the U.S. Department of Commerce, creating some concerns to Brazil, guiding it to the Dispute Settlement Body at the World Trade Organization to discuss those measures at the WTO.

INDICADORES: Medidas anti-dumping - Suco de Laranja Brasileiro Importação Estados Unidos

KEY-WORDS: Anti-dumping measures - Brazilian Orange Juice - United States Importation 


\section{INTRODUÇÃO}

O presente artigo trata das medidas de defesa comercial, ou seja, medidas antidumping, medidas compensatórias e medidas de salvaguarda.

No entanto, em conformidade com o estudo do caso concreto apresentado, será dada ênfase as medidas antidumping, medidas estas impostas para proteção da indústria nacional, visto que ocorrem quando há importação de determinado produto, e seu preço é inferior ao preço do produto da indústria doméstica, o que torna o dumping uma prática comercial desleal.

O caso analisado será o das importações de suco de laranja brasileiro pelos Estados Unidos, o que acarretou na aplicação de medidas antidumping, visto o preço que o produto fora vendido no país importador.

Serão analisados os casos apresentados no Departamento de Comércio dos Estados Unidos e no âmbito da Organização Mundial do Comércio, o pedido de consulta elaborado pelo Brasil, em decorrência da abusividade das medidas antidumping impostas pelos Estados Unidos, incorrendo na prática do "zeroing", prática esta que não respeita o Órgão de Apelação da OMC.

\section{MEDIDAS DE DEFESA COMERCIAL}

Medidas de defesa comercial, no entendimento de Antonio Carlos Rodrigues do Amaral, "são um conjunto de mecanismos jurídicos que um Estado pode utilizar para proteger suas indústrias dos danos causados por práticas desleais de comércio ou pelo crescimento imprevisto de importações". 1

Estas medidas de defesa comercial são as medidas antidumping, medidas compensatórias e medidas de salvaguarda.

Estes acordos foram inseridos no ordenamento jurídico brasileiro através do Decreto no 1355/94, que promulgou a Ata Final que incorpora os resultados da Rodada do Uruguai de Negociações Comerciais Multilaterais do GATT, assinada em Marraqueche em 12 de abril de 1994.

\footnotetext{
${ }^{1}$ AMARAL, Antônio Carlos Rodrigues. Direito do Comercio Internacional, pg. 103.
}

Revista Brasileira de Direito Internacional, Curitiba, v.7, n.7, jan./jun.2008 
A Ata da Rodada do Uruguai foi aprovada pelo Congresso Nacional pelo Decreto Legislativo ํo 30 de 15 de dezembro de 2004.

Estas medidas de defesa comercial são medidas de defesa da indústria nacional, oriundas das práticas comerciais desleais, como o dumping e subsídios, e ainda do crescente número de importações, como a salvaguarda. ${ }^{2}$

\subsection{MEDIDAS ANTIDUMPING}

As medidas antidumping estão previstas no Decreto no 1.602/95 e no Acordo de Implementação do artigo VI do GATT - General Agreement of Tariffs and Trade 1994.

Para Barral dumping pode ser definido como "a discriminação de preços entre dois mercados nacionais, entre o mercado exportador e 0 mercado importador".

O artigo 2 do Acordo de Implementação do artigo VI do GATT 1994 aduz que

A product is to be considered as being dumped, i.e. introduced into the commerce of another country at less than its normal value, if the export price of the product exported from one country to another is less than the comparable price, in the ordinary course of trade, for the like product when destined for consumption in the exporting country.

Ao contrário das medidas de salvaguarda, e em consonância com as medidas compensatórias, o dumping decorre de uma prática comercial desleal, visto que ocorre quando um produto, ao ser exportado, tem seu preço de exportação inferior ao preço do mercado interno, prejudicando assim a indústria doméstica.

Na visão de Amaral,

O dumping, por si só, não é considerado uma prática comercial desleal, mas será condenado sempre que a discriminação de preços

\footnotetext{
${ }^{2}$ FARIA, Fabio Martins. A defesa comercial: origens e regulamentação das medidas antidumping, compensatórias e de salvaguardas, pg. 41-42.

${ }^{3}$ BARRAL, Welber. Medidas Antidumping. In: BARRAL, Welber (org.) O Brasil e a OMC: os interesses brasileiros e as futuras negociações multilaterais, p. 391.
}

Revista Brasileira de Direito Internacional, Curitiba, v.7, n.7, jan./jun.2008 
estiver causando, ou ameaçando a causar, dano material à indústria nacional do produto similar ao produto importado. Nesse caso, o Estado, cuja indústria está sendo prejudicada ou ameaçada, poderá valer-se de uma sobretaxa na alíquota de importação, denominada medida antidumping, para proteger a sua indústria. ${ }^{4}$

"O dumping é uma prática privada (da empresa produtora ou exportadora estrangeira), não sendo condenada de per si, mas apenas se vier a causar ou ameaçar dano à indústria doméstica do país importador" afirma Fabio Martins Faria. ${ }^{5}$

Para a aplicação das medidas antidumping o importador deve provar que existe dano ou ameaça deste a indústria doméstica e o nexo causal entre o dano e o dumping praticado pelo exportador. E, desta forma, o país importador poderá aplicar a medida cabível sobre o produto importado. ${ }^{6}$

Assim, o dumping não é proibido pelo acordo de Implementação do artigo VI do GATT 1994, ou Acordo Antidumping. As medidas antidumping apenas serão impostas no caso do dumping causar ameaça de dano ou dano a indústria nacional. ${ }^{7}$

Para a aplicação das medidas antidumping mister se faz investigação, em conformidade com os artigos 18 e ss. do Decreto 1.602/95.

No entanto, será encerrada a investigação sem a aplicação de medidas antidumping nos seguintes casos:

a)não houve comprovação suficiente da existência de dumping ou de dano dele decorrente;

b)a margem de dumping for de minimis (inferior a 2\%); ou

c)o volume de importações objeto de dumping for insignificante (inferior a $3 \%)^{8}$

As medidas têm caráter provisório, não podendo exceder o prazo máximo de 4 meses.

\footnotetext{
${ }_{5}^{4}$ AMARAL, Antônio Carlos Rodrigues. Direito do Comercio Internacional, p. 104.

${ }^{5}$ FARIA, Fabio Martins. A defesa comercial: origens e regulamentação das medidas antidumping, compensatórias e de salvaguardas, P. 43.

${ }^{6}$ BARRAL, Welber. Medidas Antidumping. In: BARRAL, Welber (org.) O Brasil e a OMC: os interesses brasileiros e as futuras negociações multilaterais p. 391.

7 BARROS, Maria Carolina Mendonça de. Antidumping e protecionismo, p. 30.

8 FARIA, Fabio Martins. A defesa comercial: origens e regulamentação das medidas antidumping, compensatórias e de salvaguardas, P. 44.
}

Revista Brasileira de Direito Internacional, Curitiba, v.7, n.7, jan./jun.2008 
Cabe aos Ministros de Estado da Indústria, Comércio e Turismo e Ministro da Fazenda a decisão de aplicar as medidas antidumping provisórias ou em caráter definitivo e ainda, homologar compromissos de preços, com base em parecer da SECEX - Secretaria de Comércio Exterior, e é esta a responsável para promover o processo administrativo de investigação, do Ministério da Indústria, Comércio e Turismo, para comprovar a existência de dumping e dano caudado pelo mesmo (Art. 2ำ e 3ํ do Decreto $n^{0}$ 1.602/95).

Cabe ressaltar ainda que não é possível a incorrer a medida antidumping e medida compensatória na mesma importação de determinado produto. $^{9}$

\subsection{MEDIDAS COMPENSATÓRIAS}

Regulamentado no Brasil pelo Decreto nำ 1.751/1995 e pelo Acordo de Subsídios e Medidas Compensatórias que regulamentou o artigo VI e XVI do GATT 1947, o qual foi elaborado durante a Rodada do Uruguai, as medidas compensatórias serão aplicadas caso haja subsídios, que são valores pagos pelo Estado ou entidades estatais como incentivo a produção de bens destinados a exportação.

Assim, "as medidas compensatórias tem como objetivo eliminar o dano (ou ameaça de dano) causado à indústria doméstica pela importação de produto beneficiado por subsídio concedido no país exportador". 10

No entanto, antes da explanação sobre a aplicação das medidas compensatórias, mister se faz uma análise mais profunda sobre subsídios.

Para Amaral, "Subsídio é toda contribuição financeira concedida pelo governo, por órgão governamental ou por órgão privado desempenhando funções tipicamente governamentais, que beneficie uma industria específica". ${ }^{11}$

\footnotetext{
${ }^{9}$ Art. $1^{\circ}, \S 2^{\circ}$ do Decreto $\mathrm{n}^{\circ}$ 1.602/95. Em cumprimento ao disposto no Parágrafo 5 do Artigo VI do GATT/1994, a importação de um produto não poderá estar sujeita, simultaneamente, à aplicação do direito antidumping e de direito compensatório, de que trata o Acordo sobre Subsídios e Medidas Compensatórias do GATT/1994.

${ }_{10}^{10}$ BARROS, Maria Carolina Mendonça de. Antidumping e protecionismo p. 46.

${ }^{11}$ AMARAL, Antônio Carlos Rodrigues. Direito do Comercio Internacional, p. 105.
}

Revista Brasileira de Direito Internacional, Curitiba, v.7, n.7, jan./jun.2008 
Assim, existe uma classificação de subsídios em: a) subsídios proibidos; b) subsídios recorríveis e c) subsídios permitidos.

Os subsídios proibidos ou "vermelhos"12 são aqueles que estão vinculados ao desempenho do exportador ou ainda os que são vinculados preferencialmente ao uso de produtos nacionais em relação aos importados.

O artigo $3^{0}$ do Acordo sobre subsídios e medidas compensatórios define os subsídios proibidos como

Except as provided in the Agreement on Agriculture, the following subsidies, within the meaning of Article $1^{13}$, shall be prohibited: (a) subsidies contingent, in law or in fact, whether solely or as one of several other conditions, upon export performance, including those illustrated in Annex I; (b) subsidies contingent, whether solely or as one of several other conditions, upon the use of domestic over imported goods.

Os subsídios recorríveis, "amarelos"14 ou acionáveis são aqueles que causam dano ou ameaça de dano a indústria nacional de outro membro da OMC, anulação ou prejuízo de vantagens para os Membros do GATT 1994 e ainda dano grave aos interesses de um membro.

Previsto no artigo $5^{\circ}$ do Acordo de Subsídios e Medidas Compensatórias o qual estabelece que

No Member should cause, through the use of any subsidy referred to in paragraphs 1 and 2 of Article 1, adverse effects to the interests of other Members, i.e.: (a) injury to the domestic industry of another Member; (b) nullification or impairment of benefits accruing directly or indirectly to other Members under GATT 1994 in particular the benefits of concessions bound under Article II of GATT 1994; (c) serious prejudice to the interests of another Member.

O artigo $5^{\circ}$ e 6ำ do Decreto n 1.571/1995 diz que os subsídios serão acionáveis caso sejam específicos, isto é, se eles forem destinados a determinadas empresas.

E por fim, os subsídios permitidos ou irrecorríveis são aqueles destinados a atividade de pesquisa ou de ensino superior, assistência a uma região desenvolvida dentro do território de um membro e ainda assistência para

\footnotetext{
12 AMARAL, Antônio Carlos Rodrigues. Direito do Comercio Internacional, p. 105.

${ }_{13}^{13} \mathrm{O}$ artigo 1 do Acordo de Subsídios e Medidas Compensatórias conceitua subsídio.

${ }^{14}$ AMARAL, Antônio Carlos Rodrigues. Direito do Comercio Internacional, p. 105.
} 


\title{
adaptar instalações existentes a novas exigências ambientalistas que foram impostas por lei.
}

\section{Assim estabelece o artigo 8.2 do Acordo de Subsídios e Medidas}

\author{
Compensatórias:
}

Notwithstanding the provisions of Parts III and V, the following subsidies shall be non-actionable:

(a) assistance for research activities conducted by firms or by higher education or research establishments on a contract basis with firms ifthe assistance covers not more than 75 per cent of the costs of industrial research or 50 per cent of the costs of pre-competitive development activity, and provided that such assistance is limited exclusively to: (i) costs of personnel (researchers, technicians and other supporting staff employed exclusively in the research activity); (ii) costs of instruments, equipment, land and buildings used exclusively and permanently (except when disposed of on a commercial basis) for the research activity; (iii) costs of consultancy and equivalent services used exclusively for the research activity, including bought-in research, technical knowledge, patents, etc.; (iv) additional overhead costs incurred directly as a result of the research activity; (v) other running costs (such as those of materials, supplies and the like), incurred directly as a result of the research activity.

(b) assistance to disadvantaged regions within the territory of a Member given pursuant to a general framework of regional development and non-specific (within the meaning of Article 2) within eligible regions provided that: (i) each disadvantaged region must be a clearly designated contiguous geographical area with a definable economic and administrative identity; (ii) the region is considered as disadvantaged on the basis of neutral and objective criteria, indicating that the region's difficulties arise out of more than temporary circumstances; such criteria must be clearly spelled out in law, regulation, or other official document, so as to be capable of verification; (iii) the criteria shall include a measurement of economic development which shall be based on at least one of the following factors: - one of either income per capita or household income per capita, or GDP per capita, which must not be above 85 per cent of the average for the territory concerned; - unemployment rate, which must be at least 110 per cent of the average for the territory concerned; as measured over a three-year period; such measurement, however, may be a composite one and may include other factors.

(c) assistance to promote adaptation of existing facilities to new environmental requirements imposed by law and/or regulations which result in greater constraints and financial burden on firms, provided that the assistance: (i) is a one-time non-recurring measure; and (ii) is limited to 20 per cent of the cost of adaptation; and (iii) does not cover the cost of replacing and operating the assisted investment,

Revista Brasileira de Direito Internacional, Curitiba, v.7, n.7, jan./jun.2008 
which must be fully borne by firms; and (iv) is directly linked to and proportionate to a firm's planned reduction of nuisances and pollution, and does not cover any manufacturing cost savings which may be achieved; and (v) is available to all firms which can adopt the new equipment and/or production processes.

\section{Na lição de Fabio Martins Faria}

A concessão de um subsídio é uma prática governamental, definida como a outorga de um benefício, seja na forma de sustentação de renda ou de preços, seja na forma de contribuição financeira pelo governo ou órgão público, tais como: transferências de fundos, via doações, empréstimos, aportes de capital ou garantia de empréstimo; perdão ou não recolhimento de receitas públicas devidas; fornecimento de bens ou serviços que não os destinados à infraestrutura geral, ou compra de bens; ou pagamentos a um mecanismo de fundo. A ocorrência de subsídio como prática governamental será caracterizada ainda que o governo dê instruções ou confie à entidade privada a incumbência de concedê-lo. ${ }^{15}$

A aplicação das medidas compensatórias provisórias deve ser antecedida de uma investigação e seu prazo é de no máximo 5 anos (art. 66 do Decreto no 1.751/95), e, compete a aplicação dessas medidas e caráter provisório ou definitivo aos Ministros de Estado da Indústria, Comércio e Turismo e Ministro da Fazenda com base em parecer que comprove subsídio e dano decorrente do mesmo da SECEX - Secretaria de Comércio Exterior, do Ministro da Indústria, do Comércio e Turismo (art. $2^{\circ}$ do mesmo diploma legal).

\subsection{MEDIDAS DE SALVAGUARDA}

As medidas de salvaguardas são regulamentadas pelo ordenamento jurídico brasileiro pelos Decretos $n^{\circ} 1.488 / 95,1.936 / 96$ que alterou disposições de procedimentos administrativos do decreto anterior e ainda o Decreto $\mathrm{n}^{\circ}$ 2.667/98 que regulamenta a aplicação de medidas de salvaguardas às importações provenientes de Países não membros do Mercado Comum do Sul (MERCOSUL), o qual executa o Décimo Nono Protocolo Adicional ao Acordo

\footnotetext{
${ }^{15}$ FARIA, Fabio Martins. A defesa comercial: origens e regulamentação das medidas antidumping, compensatórias e de salvaguardas, P. 44.
}

Revista Brasileira de Direito Internacional, Curitiba, v.7, n.7, jan./jun.2008 
de Complementação Econômica $n^{\circ} 18$ entre Brasil, Argentina, Paraguai e Uruguai.

Os Decretos são resultados da Rodada do Uruguai, que ocorreu entre os anos de 1986 à 1992, a fim de regulamentar o artigo XIX do GATT 1947, que dispõe sobre as medidas de salvaguardas.

Assim, o Acordo de Salvaguardas dita em seu artigo 2 que estabelece as condições de aplicação da medida que

A Member may apply a safeguard measure to a product only if that Member has determined, pursuant to the provisions set out below, that such product is being imported into its territory in such increased quantities, absolute or relative to domestic production, and under such conditions as to cause or threaten to cause serious injury to the domestic industry that produces like or directly competitive products. ${ }^{16}$

O objetivo do artigo XIX do GATT é permitir aos Membros um reequilíbrio após uma situação inesperada ou imprevista no mercado de importação de produtos, fato este que permite a adaptação da indústria doméstica nas novas formas de concorrência pelo aumento dessas importações. ${ }^{17}$

Segundo a definição de Fábio Martins Faria

Salvaguardas são medidas de caráter não seletivo e temporário, na forma de elevações tarifárias ou limitações quantitativas, que têm como objetivo proteger uma indústria doméstica de prejuízo grave causado ou que possam ser causados por importações crescentes, tendo por objetivo facilitar o ajuste competitivo dessa indústria, que não se encontra em condições de concorrer com as importações. ${ }^{18}$

As medidas de salvaguarda serão aplicadas quando o número de importações afetar de maneira significativa o mercado nacional, ou seja, trouxer prejuízo grave ou ameaça de prejuízo grave a indústria doméstica. ${ }^{19}$

\footnotetext{
${ }^{16}$ http://www.wto.org/english/docs_e/legal_e/25-safeg_e.htm

17 BROGINI, Gilvan Damiani. Medidas de Salvaguarda e Uniões Aduaneiras, p. 27.

18 BROGINI, Gilvan Damiani. Medidas de Salvaguarda e Uniões Aduaneiras, p. 47.

${ }^{19} \mathrm{O}$ conceito de prejuízo grave e ameaça de prejuízo grave está definido na Lei, através do Decreto $n^{\circ 1.488 / 95}$, em seu artigo $6^{\circ}$, e ainda no artigo $4^{\circ}$ do Decreto $2.667 / 98$.

Art. $6^{\circ}$ Para efeitos desse regulamento, entender-se-á por:

I- prejuízo grave: a deterioração geral significativa da situação de uma determinada indústria doméstica;
}

Revista Brasileira de Direito Internacional, Curitiba, v.7, n.7, jan./jun.2008 
Fracionando o conceito de Fábio Faria Martins temos que as salvaguardas são medidas de caráter não seletivo.

Isto significa que as medidas serão impostas ao produto importado não levando em consideração a sua procedência, ou seja, o local em que foi produzido, com base no princípio da Nação Mais Favorecida, pois não importa da onde adveio o produto, com exceção nos casos relativos a produtos têxteis, conforme artigo $5^{\circ}$ do Decreto $n^{0} 1.488 / 95^{20}$

Assim, "qualquer medida de salvaguarda aplicada deve atingir todas as importações do produto que a motivou, independente de origem". 21

É o mesmo que estabelece o artigo 2.2 do Acordo de Salvaguardas. ${ }^{22}$

Em relação ao lapso temporal das medidas de salvaguardas, elas são, em regra, temporárias, podendo ser definitivas conforme estipulado em lei.

As medidas em caráter provisório serão aplicadas se houver prejuízo de dano grave ou de difícil reparação, ou seja, se houver uma situação critica em que o aumento das importações esteja afetando a indústria nacional. ${ }^{23}$

Existe um prazo máximo de duração destas medidas, qual seja de 200 dias. No entanto este prazo pode ser suspenso antes do seu final por decisão interministerial, como preceitua o $\S 1^{\circ}$ do art. $4^{\circ}$ do Decreto nํㅜ 1.488/95.

As medidas de salvaguarda serão aplicadas através de alíquota ad valorem, alíquota específica ou uma combinação de ambas. ${ }^{24}$ No caso da alíquota ad valorem, esta será um plus ao imposto de importação.

As medidas provisórias poderão tornar-se definitivas, e caso isso ocorra o seu tempo de vigência será incorporado ao tempo de vigência total da medida, para prevenir ou reparar prejuízo grave, pelas mesmas modalidades

II- ameaça de prejuízo grave: o prejuízo grave claramente iminente, determinado com base nos fatos e não apenas em alegações, conjecturas ou possibilidades remotas;

III- indústria doméstica a proveniente do conjunto dos produtores de bens similares ou diretamente concorrentes estabelecidos no território brasileiro, ou aqueles, cuja produção conjunta de bens similares ou diretamente concorrentes constitua uma proporção substancial da produção nacional de tais bens.

20 Art. 5o As medidas de salvaguarda provisória serão aplicadas ao produto importado independentemente de sua origem, exceto nos casos previstos nas disposições transitórias aplicáveis a produtos têxteis.

${ }^{21}$ BROGINI, Gilvan Damiani. Medidas de Salvaguarda e Uniões Aduaneiras, p. 33.

${ }^{22}$ Article 2:Conditions

2. Safeguard measures shall be applied to a product being imported irrespective of its source.

${ }^{23}$ Art. 4을 do Decreto 1.488/95.

${ }^{24} \S 2^{\circ}$ do art. $4^{\circ}$ do Decreto № $^{\circ} 1.488 / 95$.

Revista Brasileira de Direito Internacional, Curitiba, v.7, n.7, jan./jun.2008 
das medidas de caráter provisório, ou seja, alíquota ad valorem, alíquota específica ou ambas e ainda restrições quantitativas, e neste caso, as importações não serão reduzidas abaixo de um nível de um lapso temporal recente.

De qualquer sorte, as medidas de salvaguarda não poderão ser superiores a 4 anos.

Ao contrário das medidas antidumping e medidas compensatórias, no caso das medidas de salvaguarda existe uma prática comercial leal, isto é, apenas é aplicada nos casos em que houve um aumento gradativo nas importações e este aumento gera ameaça ou prejuízo a indústria nacional. ${ }^{25}$

$\mathrm{Na}$ ótica de Brogini, para saber se realmente houve um aumento significativo no número de importações

Exige-se uma análise do ritmo (direção e velocidade) e cifra do aumento das
importações, em termos absolutos e relativos (neste último caso, como
percentual da produção nacional). Tanto em um quanto em outro caso, deve-
se levar em conta, para efeitos de análise, todo o período utilizado como
referência, e não apenas determinados anos ou apenas as pontas do período. ${ }^{26}$

E por fim, para a aplicação das medidas de salvaguardas mister se faz um prévio processo investigatório.

Assim, reza o artigo $3^{\circ}$ do Acordo sobre Salvaguardas que

A Member may apply a safeguard measure only following an investigation by the competent authorities of that Member pursuant to procedures previously established and made public in consonance with Article $\mathrm{X}$ of GATT 1994.

A investigação irá apurar se realmente houve ameaça a prejuízo grave ou prejuízo grave para que sejam aplicadas as medidas.

Este procedimento deve garantir as partes interessadas e a terceiros o direito a ampla defesa e deve ser público, com exceção das informações confidenciais. $^{2728}$

\footnotetext{
${ }^{25}$ AMARAL, Antônio Carlos Rodrigues. Direito do Comercio Internacional, p. 106.

${ }^{26}$ BROGINI, Gilvan Damiani. Medidas de Salvaguarda e Uniões Aduaneiras, p. 25.

27 BROGINI, Gilvan Damiani. Medidas de Salvaguarda e Uniões Aduaneiras, p. 24.

${ }^{28}$ Agreement on Safeguards - Article 3:Investigation
} 


\section{APLICAÇÃO DE MEDIDAS ANTIDUMPING PELOS ESTADOS UNIDOS NA IMPORTAÇÃO DE SUCO DE LARANJA BRASILEIRO}

O caso concreto de que trata o presente artigo é a aplicação de medida antidumping pelos Estados Unidos ao suco de laranja exportado pelo Brasil.

A medida foi imposta pela Comissão de Comércio Internacional dos Estados Unidos (USITC), através de uma votação no dia 8 de fevereiro de 2006, onde foi concluído que as importações feitas pelo Brasil causavam prejuízo grave a industria doméstica americana, visto que as importações de suco de laranja pelo Brasil alcançaram valor superior a US\$ 98 milhões no ano de 2004, valor que apresentou significativa queda se comparado ao apresentado no ano de 2003, no importe de US\$ 158 milhões. ${ }^{29}$

O quadro abaixo, com estatísticas oriundas do Departamento de Comércio dos Estados Unidos mostra os números de importações e os valores relativos as mesmas ${ }^{30}$ :

\begin{tabular}{|c|c|c|c|c|}
\hline & 2002 & 2003 & Jan-Nov 2003 & Jan-Nov 2004 \\
\hline Volume (litros) & $446,649,835$ & $876,398,111$ & $809,940,730$ & $572,606,633$ \\
\hline
\end{tabular}

1. A Member may apply a safeguard measure only following an investigation by the competent authorities of that Member pursuant to procedures previously established and made public in consonance with Article X of GATT 1994. This investigation shall include reasonable public notice to all interested parties and public hearings or other appropriate means in which importers, exporters and other interested parties could present evidence and their views, including the opportunity to respond to the presentations of other parties and to submit their views, inter alia, as to whether or not the application of a safeguard measure would be in the public interest. The competent authorities shall publish a report setting forth their findings and reasoned conclusions reached on all pertinent issues of fact and law.

2. Any information which is by nature confidential or which is provided on a confidential basis shall, upon cause being shown, be treated as such by the competent authorities. Such information shall not be disclosed without permission of the party submitting it. Parties providing confidential information may be requested to furnish non-confidential summaries thereof or, if such parties indicate that such information cannot be summarized, the reasons why a summary cannot be provided. However, if the competent authorities find that a request for confidentiality is not warranted and if the party concerned is either unwilling to make the information public or to authorize its disclosure in generalized or summary form, the authorities may disregard such information unless it can be demonstrated to their satisfaction from appropriate sources that the information is correct.

${ }^{29}$ Embaixada dos Estados Unidos no Brasil. http://embaixadaamericana.org.. r $/$ index. php?action=materia\&id=4146\&submenu=press. inc. . php\&itemmenu=21

${ }^{30}$ Departament of Commerce of United States - Initiation of Antidumping Duty Investigation on Imports of Certain Orange Juice from Brazil. http://www.ita.doc.gov/media/FactSheet/0205/oj_020805.html.

Revista Brasileira de Direito Internacional, Curitiba, v.7, n.7, jan./jun.2008 


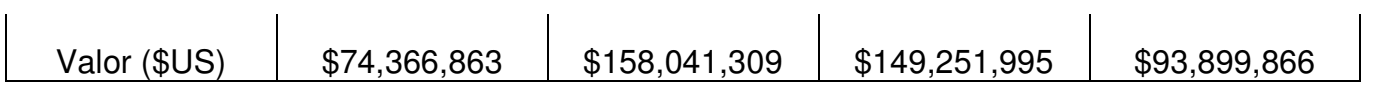

O início da investigação do imposto antidumping na importação de certos tipos de sucos de laranja brasileiros foi anunciado no dia 8 de fevereiro de 2005 pelo Departamento de Comércio dos Estados Unidos. ${ }^{31}$

Duas formas de suco de laranja são objeto da investigação para aplicação do imposto antidumping, quer para transporte, quer para manufatura, sejam elas: a) suco de laranja congelado e altamente concentrado, denominado "Frozen concentrated orange juice for further manufacturing" (FCOJM) e b) suco de laranja pasteurizado e não concentrado, conhecido como "Not-from-concentrated" (NFC) ${ }^{32}$

De acordo com o Departamento de Comércio dos Estados Unidos, a petição entregue na data de 27 de dezembro de 2004 foi assinada por: Florida Citrus Mutual; A. Duda \& Songs, com nome comercial Citrus Belle; Citrus World, Inc.; Peace River Citrus Products, Inc. e Southern Garden Citrus Processing Corp., com nome comercial Southern Gardens ${ }^{33}$.

Todas as empresas que são peticionarias no presente caso estão localizadas no Estado da Flórida ${ }^{34}$.

$\mathrm{Na}$ data de 17 de agosto de 2005, foi anunciada pelo Departamento de Comercio americano uma determinação preliminar da investigação do imposto antidumping dos sucos de laranja provenientes do Brasil.

Em caráter preliminar (Caso ำ A-351-840), o Departamento de Comércio verificou que os exportadores brasileiros de suco de laranja vendiam

\footnotetext{
${ }^{31}$ Departament of Commerce of United States - Initiation of Antidumping Duty Investigation on Imports of Certain Orange Juice from Brazil. http://www.ita.doc.gov/media/FactSheet/0205/oj_020805.html.

${ }^{32}$ Departament of Commerce of United States - Initiation of Antidumping Duty Investigation on Imports of Certain Orange Juice from Brazil. http://www.ita.doc.gov/media/FactSheet/0205/oj_020805.html.

${ }^{33}$ Departament of Commerce of United States - Initiation of Antidumping Duty Investigation on Imports of Certain Orange Juice from Brazil. http://www.ita.doc.gov/media/FactSheet/0205/oj_020805.html.

${ }_{34}$ Departament of Commerce of United States - Preliminary Determination in the Antidumping Duty Investigation on Imports of Certain Orange Juice from Brazil (A-351-840). http://ia.ita.doc.gov/download/factsheets/factsheet-brazil-oj-prelim-081605.pdf.
}

Revista Brasileira de Direito Internacional, Curitiba, v.7, n.7, jan./jun.2008 
o produto no mercado americano com valor inferior ao valor real, com margens que variavam de 24.62 a $60,29 \%$, conforme quadro abaixo ${ }^{35}$ :

\begin{tabular}{|c|c|}
\hline Produtor/Exportador & Margem \\
\hline Fisher S/A - Agroindústria & $31.04 \%$ \\
\hline $\begin{array}{c}\text { Montecitrus Indústria e Comércio } \\
\text { Limitada }\end{array}$ & $60.29 \%$ \\
\hline Sucocitrico Cutrale, S.A. & $24.62 \%$ \\
\hline Outros & $21.16 \%$ \\
\hline
\end{tabular}

O resultado desta determinação foi a instrução do U.S. Customs e Border Protection por parte do Departamento de Comércio para recolher depósito em dinheiro ou firmar acordo das taxas das margens finais de importação do produto objeto da presente investigação. ${ }^{36}$

A determinação final do caso foi anunciada no dia 09 de janeiro do ano de 2006, com informações de que produtores brasileiros exportavam suco de laranja por um preço inferior ao valor real do produto, com margens de antidumping variando entre 9.73 a $60.29 \%$, conforme dados a seguir ${ }^{37}$ :

\begin{tabular}{|c|c|}
\hline Produtor/Exportador & Margem \\
\hline Fisher S/A - Agroindústria & $9.73 \%$ \\
\hline Montecitrus Trading, S.A & $60.29 \%$ \\
\hline Sucocitrico Cutrale, S.A. & $19.19 \%$ \\
\hline Outros & $15.42 \%$ \\
\hline
\end{tabular}

\footnotetext{
${ }^{35}$ Departament of Commerce of United States - Preliminary Determination in the Antidumping Duty Investigation on Imports of Certain Orange Juice from Brazil (A-351-840). http://ia.ita.doc.gov/download/factsheets/factsheet-brazil-oj-prelim-081605.pdf.

${ }^{36}$ Departament of Commerce of United States - Preliminary Determination in the Antidumping Duty Investigation on Imports of Certain Orange Juice from Brazil (A-351-840). http://ia.ita.doc.gov/download/factsheets/factsheet-brazil-oj-prelim-081605.pdf.

37 Departament of Commerce - United States of América. Final Determination in the Antidumping Duty Investigation on Imports of Orange Juice From Brazil. http://www.ita.doc.gov/media/FactSheet/0106/oj_010906.html
}

Revista Brasileira de Direito Internacional, Curitiba, v.7, n.7, jan./jun.2008 
Os resultados alcançados pela determinação final foram os mesmos alcançados anteriormente pela determinação preliminar, conforme explanado anteriormente.

O Brasil, na data de 27 de novembro de 2008, apresentou na Organização Mundial do Comércio (OMC) pedido de consulta (Dispute DS382) aos Estados Unidos: Revisão Administrativa anti-dumping e outras medidas relacionadas a importação de determinados tipos de suco de Laranja do Brasil $^{38}$.

O pedido está relacionado ao Caso nํ A-351-840 do Departamento de Comércio dos Estados Unidos, referente a importação de determinados tipos de suco de laranja.

O referido caso trata da revisão administrativa de antidumping do período de 24 de agosto de 2005 a 28 de fevereiro de 2007 cujo resultado foi publicado na data de 11 de agosto de 2008 ("Certain Orange Juice from Brazil: Final Results and Partial Rescission of Antidumping Duty Administrative Review'), bem como instruções de avaliação e depósito em dinheiro (05 de agosto de 2008), que argumenta o aumento nos lançamentos, confirmando que houve aplicação do "zeroing" por parte do Departamento de Comércio dos Estados Unidos), não respeitando as decisões do Órgão de Apelação da OMC. $^{39}$

O pedido questiona também as decisões tomadas pelo United States Customs and Border Protection para recolher em caráter definitivo impostos antidumping sobre a taxa de avaliação do imposto na revisão feita no período de 24 de agosto de 2005 a 28 de fevereiro de $2007 .{ }^{40}$

Outra preocupação do Brasil são as leis americanas, regulamentações, procedimentos administrativos, práticas e metodologia, metodologia esta empregada pelos Estados Unidos para determinar as taxas de dumping nas

\footnotetext{
${ }^{38}$ World Trade Organization. United States - Anti-Dumping Administrative Reviews and Other Measures Related to Imports of Certain Orange Juice from Brazil. http://www.wto.org/english/tratop_e/dispu_e/cases_e/ds382_e.htm

${ }^{39}$ World Trade Organization. United States - Anti-Dumping Administrative Reviews and Other Measures Related to Imports of Certain Orange Juice from Brazil. http://www.wto.org/english/tratop_e/dispu_e/cases_e/ds382_e.htm

${ }^{40}$ World Trade Organization. United States - Anti-Dumping Administrative Reviews and Other Measures Related to Imports of Certain Orange Juice from Brazil. http://www.wto.org/english/tratop_e/dispu_e/cases_e/ds382_e.htm
}

Revista Brasileira de Direito Internacional, Curitiba, v.7, n.7, jan./jun.2008 
revisões administrativas, de acordo com o Departamento de Comércio americano. ${ }^{41}$

O Brasil afirma que as margens de dumping são aumentadas pelo fato do cálculo ser feito através do "zeroing".

Por meio desta prática comercial, o preço individual de exportação é maior do que o valor normal ${ }^{42}$, o que impede que as transações compensem as exportações realizadas com valor menor do que o valor normal.

Até a presente data, não houve decisão do Órgão de Solução de Controvérsias da OMC.

\section{CONSIDERAÇÕES FINAIS}

Mesmo em virtude da irresignação por parte das indústrias americanas produtoras de suco de laranja, ao verem a importação dos Estados Unidos de suco de laranja brasileiro afetar sua indústria nacional, e terem apresentado petição ao Departamento de Comércio Americano para imposição de medidas antidumping, esta foi feita de maneira abusiva, motivo pela qual ensejou pedido de consultas destas medidas a Organização Mundial do Comércio.

As medidas aplicadas pelo Departamento do Comércio americano preocuparam o Brasil em relação as leis, regulamentações, procedimentos administrativos, práticas e metodologias, principalmente a prática de "zeroing", que não está de acordo com a opinião da $\mathrm{OMC}$, e vem sendo praticada usualmente pelos Estados Unidos.

Houve, realmente, um grande prejuízo a indústria doméstica norteamericana com a importação de suco de laranja originário do Brasil, em especial no Estado da Flórida, que é o maior produtor de laranja dos Estados Unidos, fato é que todas as peticionarias do caso apresentado ao Departamento de Comércio estão situadas no referido Estado.

\footnotetext{
${ }^{41}$ World Trade Organization. United States - Anti-Dumping Administrative Reviews and Other Measures Related to Imports of Certain Orange Juice from Brazil. http://www.wto.org/english/tratop_e/dispu_e/cases_e/ds382_e.htm

${ }_{42}$ World Trade Organization. United States - Anti-Dumping Administrative Reviews and Other Measures Related to Imports of Certain Orange Juice from Brazil. http://www.wto.org/english/tratop_e/dispu_e/cases_e/ds382_e.htm
}

Revista Brasileira de Direito Internacional, Curitiba, v.7, n.7, jan./jun.2008 
Mister se faz a aplicação de medidas antidumping, mas de uma maneira correta, não ensejando práticas desleais como o "zeroing".

Cabe agora a OMC analisar se foi correta ou não a imposição da medida antidumping por parte do Departamento de Comércio norte-americano, e se os pedidos requisitados pelo Brasil devem ser motivo de preocupação por parte deste país.

\section{REFERÊNCIAS}

AMARAL, Antônio Carlos Rodrigues do. (Coord.). Direito do Comércio Internacional - Aspectos Fundamentais. São Paulo: Aduaneiras, 2004.

BARRAL, Welber. Medidas Antidumping. In: BARRAL, Welber (org.) O Brasil e a OMC: os interesses brasileiros e as futuras negociações multilaterais. Florianópolis: Diploma Legal, 2000, p. 391-408.

. A influência do Comércio Internacional no Processo de Desenvolvimento. In: BARRAL, Welber; PIMENTEL, Luiz Otávio. Comércio Internacional e Desenvolvimento. Florianópolis: Fundação Boiteux, 2006, p. 11-35.

BARROS, Maria Carolina Mendonça de. Antidumping e protecionismo. São Paulo: Aduaneiras, 2003.

BROGINI, Gilvan Damiani. Medidas de salvaguarda e uniões aduaneiras. São Paulo: Aduaneiras, 2000.

CARVALHO, Carolina Monteiro de; NEGRINI, Maria Carolina Briza. Tratado de defesa comercial: antidumping, compensatóras e salvaguardas. São Paulo: Observador Legal, 2003.

Departament of Commerce of United States - Initiation of Antidumping Duty Investigation on Imports of Certain Orange Juice from Brazil.

http://www.ita.doc.gov/media/FactSheet/0205/oj_020805.html. Acesso em 02/03/2009.

Departament of Commerce of United States - Preliminary Determination in the Antidumping Duty Investigation on Imports of Certain Orange Juice from Brazil (A-351-840). http://ia.ita.doc.gov/download/factsheets/factsheet-brazil-oj-prelim081605.pdf. Acesso em 02/03/2009.

Departament of Commerce - United States of América. Final Determination in the Antidumping Duty Investigation on Imports of Orange Juice From Brazil. http://www.ita.doc.gov/media/FactSheet/0106/oj_010906.html. Acesso em 02/03/2009.

Revista Brasileira de Direito Internacional, Curitiba, v.7, n.7, jan./jun.2008 
Embaixada dos Estados Unidos no Brasil. http://embaixadaamericana.org.br/index.php?action=materia\&id=4146\&submenu=press.inc.php \&itemmenu=21. Acesso em 01/03/2009.

FARIA, Fábio Martins. A defesa comercial: origens e regulamentação das medidas anti-dumping, compensatórias e de salvaguardas. São Paulo:

Aduaneiras, 2002.

World Trade Organization. http://www.wto.org/english/docs_e/legal_e/25safeg_e.htm. Acesso em 07.08.2008.

World Trade Organization. United States - Anti-Dumping Administrative Reviews and Other Measures Related to Imports of Certain Orange Juice from Brazil. http://www.wto.org/english/tratop_e/dispu_e/cases_e/ds382_e.htm. Acesso em 02/03/2009. 